\title{
How hot was the Holocene?
}

\author{
Basil A.S. Davis \\ Climate-12k workshop, Sainte Croix, Switzerland, 10-13 June 2019
}

Our ability to understand the natural variability of the Earth's climate before modern anthropogenic greenhouse warming relies on establishing a public network of reliable proxy-temperature records from across the terrestrial and oceanic regions of the world. The PAGES $2 \mathrm{k}$ Network (pastglobalchanges.org/2k) has been successful in extending our knowledge of the Earth's temperature variability back 2000 years, and Climate-12k was established in December 2018 to further extend it back to 12,000 years before present.

This time period includes the early-mid Holocene thermal optimum, when unequivocal evidence exists of higher-than-present temperatures, at least at higher latitudes in the Northern Hemisphere. However, the global picture of Holocene temperature change remains poorly understood, based either on very sparse data networks that manage to cover the entire Holocene, or "snap-shots" that have greater numbers of sites but only for a single time-slice, such as the mid Holocene (6000 BP).

The Climate-12k project began with an appeal for published quantitative Holocene temperature reconstructions and other temperature-sensitive multiproxy records in early 2019 that culminated in a PAGESendorsed workshop in Switzerland in June (pastglobalchanges.org/calendar/2019/127pages/1911), organized by Basil Davis (University of Lausanne), Oliver Heiri, (University of Basel), Sam Jaccard (University of Bern) and Darrell Kaufman (Northern Arizona University).

Pre-workshop activities involved compiling data from different sources and formats into a single standardized dataset. This included data from public archives and publication data supplements, as well as previously privately held data from research groups

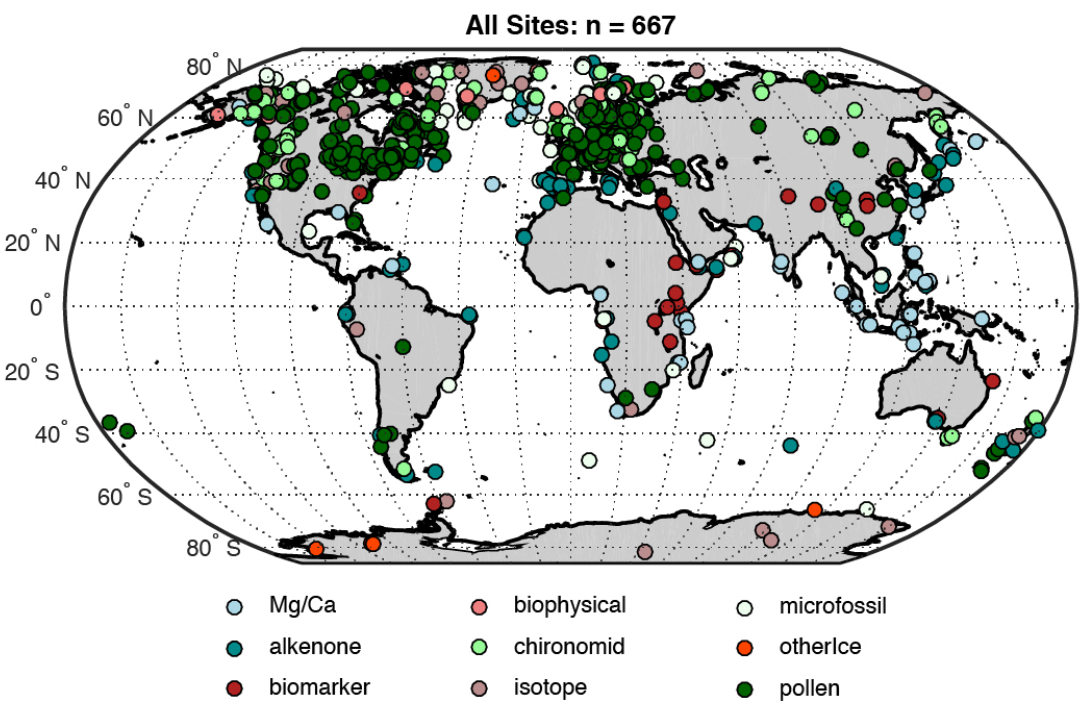

Temporal Availability

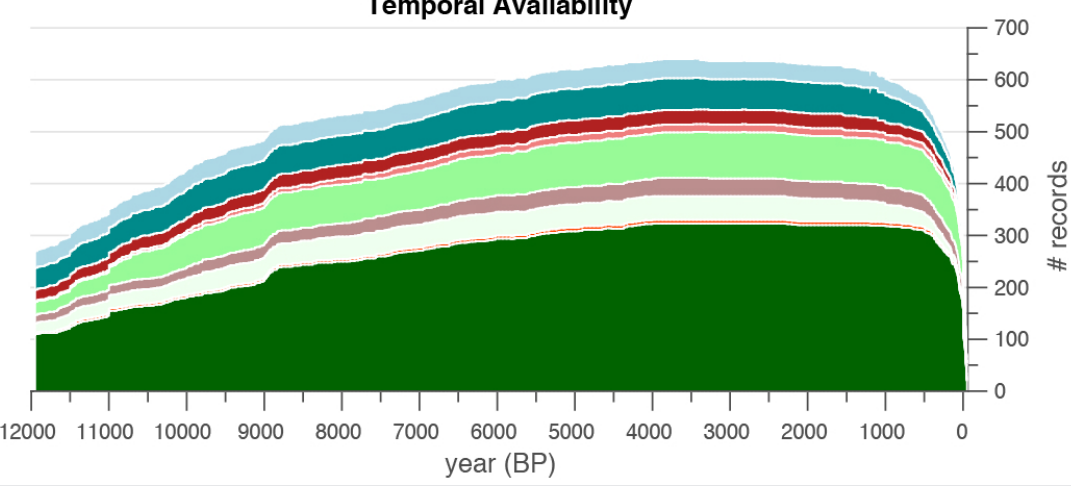

Figure 1: The global distribution of Holocene temperature records in the Climate-12k database (v.0.26)

and individual scientists. By the time of the workshop, the Climate-12k project had compiled records from over 600 sites (Fig. 1) that conformed to the project selection criteria. This focused data collection efforts on records that are at least 4000 years long, with a minimum 400-year median sampling interval and 3000-year dating interval.

The number of applications to attend the workshop greatly exceeded the 30 places that were available, which had to represent the world's main geographical regions and proxies, together with expertise in databases and data analysis as well as climate modeling.

The workshop format involved a small number of invited talks to provide background, but was mostly based around group discussions and break-out teams. These were designed to review the collected data, refine the selection criteria, agree on essential metadata, learn about the Linked Paleo Data (LiPD; lipd.net) database format, as well as discuss analysis and publication.

A key motivation behind the Climate-12k project has been to provide a new analysis of global and regional Holocene temperature trends in time for inclusion in the next IPCC report (AR6). A database publication and an analysis paper are both planned for submission before the end of the year, which is the deadline for consideration for the Working Group 1 report.

Looking further ahead to next year, it was also proposed at the workshop that a second workshop should be organized to both continue expansion of the temperature dataset, and to expand the project to include Holocene hydroclimate records. In the meantime, workshop participants were enthusiastic about a potential application to establish Climate-12k as an official PAGES working group.

\section{ACKNOWLEDGEMENTS}

This Climate-12k workshop was a PAGES-endorsed activity. It was funded by the Swiss National Science Foundation, Grant 200021_169598 "HORNET" to Basil Davis, with additional support from the University of Lausanne, the University of Basel (Oliver Heiri) and the US National Science Foundation (Darrell Kaufman).

AFFILIATION

Institute of Earth Surface Dynamics, University of Lausanne, Switzerland 